\title{
A systematic approach for predicting loyalty behavior of tourist destinations
}

\author{
Ahmad Reza Talaee Malmiri, Roxana Norouzi Isfahani, Ahmad BahooToroody and \\ Mohammad Mahdi Abaei
}

\begin{abstract}
Purpose - Destinations to be able to compete with each other need to equip themselves with as many competitive advantages as possible. Tourists' loyalty to a destination is considered as a prominent competitive tool for destinations. Tourists' loyalty manifests itself in recommendation of the destination to others, repeat visit of the destination and willingness to revisit the destination. Although a plethora of studies have tried to define models to show the relation between loyalty and the antecedent factors leading up to it, few of them have tried to integrate these models with mathematical approaches for better understanding of loyalty behavior. The purpose of this paper is to integrate a tourist destination model with Bayesian Network in order to predict the behaviour of destination loyalty and its antecedent factors.

Design/methodology/approach - This paper has developed a probability model by the integration of a destination loyalty model with a Bayesian network (BN) which enables to predict and analyze the behavior of loyalty and its influential factors. To demonstrate the application of this framework, Tehran, the capital of Iran, was chosen as a destination case study.

Findings - The outcome of this research will assist in identifying the weak key points in the tourist destination area for giving insights to the marketers, businesses and policy makers for making better decisions related to destination loyalty. In the analysis process, the most influential factors were recognized as the travel environment image, natural/historical attractions and, with a lower degree, infrastructure image which help the decision maker to detect and reinforce the weak factors and put more effort in focusing on improving the necessary parts rather than the irrelevant parts.

Originality/value - The research identified all critical factors that have the most influence on destination loyalty while driving the associate uncertainty which is significant for the tourism industry. This resulted in better decision-making which is used to identify the impact of tourism destination loyalty.
\end{abstract}

Keywords Destination image optimization, Loyalty prediction, Bayesian network

Paper type Research paper

\section{Introduction}

Tourist loyalty is considered as a competitive advantage for a destination (Almeida-Santana and Moreno-Gil, 2018; Weaver and Lawton, 2011), therefore attracting tourists and making them loyal is of a key concern for destinations managers (Hsu et al., 2009). To increase the number of inbound tourists and in consequence increasing the inbound tourism revenue, marketers should pay more and more attention to tourists' loyalty (Mohamed and Shaker, 2017). In addition, it is of great importance for tourist destination managers and policy makers to find out the elements that incorporate in tourists' loyalty to improve the attractions of a destination and accordingly to introduce better offerings, services and communication strategies that exceed tourists' expectations (Gursoy et al., 2014; Mohamed and Shaker, 2017). Tourist loyalty is also a significant contributor to a destination's success and flourish. Loyal tourists are willing to stay longer in destinations, give positive recommendations to others about the destination and as a result, lower the costs of promotions for the destination (Stylidis et al. , 2020). Destinations can be categorized according to the
Ahmad Reza Talaee Malmiri is based at the Tehran University, Tehran, Islamic Republic of Iran. Roxana Norouzi Isfahani and Ahmad BahooToroody are both based at the University of Florence, Florence, Italy. Mohammad Mahdi Abaei is based at the Delft University of Technology, Delft, The Netherlands.

Received 2 November 2020 Revised 11 March 2021 2 August 2021 Accepted 11 August 2021

(C) Ahmad Reza Talaee Malmiri, Roxana Norouzi Isfahani, Ahmad BahooToroody and Mohammad Mahdi Abaei. Published in Journal of Tourism Futures. Published by Emerald Publishing Limited. This article is published under the Creative Commons Attribution (CC BY 4.0) licence. Anyone may reproduce, distribute, translate and create derivative works of this article (for both commercial and noncommercial purposes), subject to full attribution to the original publication and authors. The full terms of this licence may be seen at http://creativecommons.org/ licences/by/4.0/legalcode 
area they cover; a destination may be defined as a country, state, region, city or town which is marketed or markets itself as a place for tourists to visit. One of the city destinations that has grown in importance through the recent years is Tehran. The statistics given by Iran's Cultural Heritage, Handicrafts and Tourism Organization show an expansion in the number of inbound tourists coming to Tehran, starting from around three million tourists in 2011 to almost five million in 2017 (CHHTOI, 2018). Tehran's tourism can boast a great potential since it encompasses so many natural and historical attractions like Alborz mountain range in the north and Iran National Museum in the heart of Tehran, yet lack of tourism-related infrastructures, lack of enough endeavor to make a good destination image and lack of strong foreign relationships, and most importantly, lack of a comprehensive domestic model of branding based on new information technology tools have made the city lag behind other tourist destination cities, in spite of its slow progression (Bidhendi et al., 2021; Shafia et al., 2019). Tehran, as a city destination has not integrated a concrete marketing plan for fostering its tourism. Although marketing a destination is quite challenging due to different reasons like the complicated relationships between different stakeholders in a specific destination, the potential contrasts in interests between these stakeholders, and lack of control and ownership of the whole chain of destination product and service supply-demand for tourists (Line and Wang, 2017), destination marketers and destination marketing organizations (DMOs) can cluster all destinationrelated stakeholders by means of designing a master plan enabling all parts to boost the image, brand and other competitive tools of a specific destination. In this circumstance, word of mouth advertisement and in respect tourists' loyalty to recommend a destination to other people as a competitive advantage may gain importance. Also, the mathematical approach has been applied to struggle with different concerns throughout the tourism sector (Baggio et al., 2010; Smeral, 1988; Tyrrell and Johnston, 2008). One of these concerns being loyalty has been explained and estimated by means of different probabilistic tools (Hsu et al., 2009; Popovic et al., 2018; Chanpariyavatevong et al., 2021). This paper aims to introduce a prediction model based on which it is possible to quantify the uncertainty of a tourist destination loyalty and find the most and least influential factors contributing to it. In this connection, a loyalty model is developed to interconnect qualitative representation of the key factors contributing to destination loyalty in causal inference, quantifying the uncertainty of the influencing parameters that highly affect tourism destinations' loyalty. In particular, to make this model capable of dynamic quantification, a probabilistic modeling tool is implemented to be able to reason under the uncertainty (Assaf and Tsionas, 2015; Hsu et al., 2009, 2012). Among the different probabilistic-prediction models, two models of maximum likelihood estimation (MLE) and Bayesian statistics were found to be recommended by the researchers (Nielsen and Sørensen, 2010). To predict the behavior of factors contributing to a subject, a Bayesian network (BN) is increasingly used due to its advantages over other methods such as fault tree analysis (FTA) as discussed by Friis-Hansen (2000), Khakzad et al. (2011) and Straub (2005). There exist three main reasons for the Bayesian method to be superior to other methods. Firstly, it is a promising tool that allows the comprehensive reflection of available knowledge about the process (Abaei et al., 2018; Arzaghi et al. , 2018; BahooToroody et al., 2019; Leoni et al. , 2019). Secondly, in comparison to other tools such as the analytic hierarchy process (AHP) and factor analysis (FA), BN performs better in quantifying the uncertainty and solving decision-making problems when extended to an influence diagram (Friis-Hansen, 2000; Zwirglmaier et al., 2015). Thirdly, in a Bayesian approach, it is also possible to convert continuous random variables into a discrete space, enabling the inference of more complicated stochastic relationships amongst many parameters (Friis-Hansen, 2000). That means each variable involved in the problem can be analyzed explicitly rather than in a binary space.

The BN as a probabilistic modeling tool has been widely implemented for uncertainty assessment in tourism systems. Hsu et al. (2009) merged the BN with the linear structural relation model (LISREL) to consider the factors affecting tourism loyalty and predict the level of the tourists' loyalty. A total of 452 valid samples from tourists with the tour experience of the Toyugi, Taiwan, were accounted for to conduct the proposed methodology. According to the previous conducted research, the established Bayesian ridge regression to a tourism data set in order to treat the biased constant as a parameter of inference. The model proposed to find the optimum solution for the multicollinearity problem as a most important misconception in the tourism research field.

PAGE 2 | JOURNAL OF TOURISM FUTURES $\mid$ VOL. $\mathbf{m} \mathbf{m}$ NO. $\mathbf{m} 2021$ 
In previous studies related to destination loyalty, different statistical methods have been used. Among these methods, some measures including explanatory and confirmatory factor analysis (Chi and Qu, 2008; Hultman et al., 2015, Sun et al., 2013), structural equation modeling (SEM) (Brida et al., 2012; Prayag and Rayan, 2012; Eusebio and Vieira, 2013) and the logit modeling (Meleddu et al., 2015; Almeida-Santana and Moreno-Gil, 2018) were more widely implemented than others. While these studies have either recognized the strength of relationships between destination loyalty and its antecedent factors or estimated the state of loyalty through regressions, none have analyzed the behavior of loyalty and its influencing factors under different uncertainty scenarios, given new evidence in a prediction model. Moreover, the tourism industry sector for planning effective, sustainable marketing strategies for destination loyalty needs to find an optimum design of sustainable destination loyalty by mapping out destination loyalty on a probabilistic/decision-making model like the BN to help DOMs come up with better plans to make tourists coming to their destinations more loyal.

This paper aims to introduce a systematic approach to analyze the factors contributing to any city destination loyalties and predict their behavior. Tehran, as a potential tourist city to attract more tourists, is introduced as a case study. In this respect, firstly, a qualitative tourist loyalty model is presented to identify casual representative factors; secondly, a survey analysis based on expert's judgment is done to obtain essential data for implementing in the probability model and thirdly, these data are integrated with the BN to predict the loyalty of the city destination. The outcome of this research will assist in identifying the weak critical points in the tourist destination area for giving insights to the marketers, businesses and policy makers in making better decisions related to destination loyalty.

\section{Tourism loyalty}

Based on the conducted research, two aspects of loyalty have been recognized: behavioral and attitudinal (Almeida-Santana and Moreno-Gil, 2017; Baloglu, 2002; Kumar et al., 2006). In behavioral loyalty, revisit intention of a destination and ongoing revisits of a destination is taken into consideration, while attitudinal loyalty manifests tourists' emotions and perceived value toward a destination that results in recommendation of that specific destination and also willingness to revisit it (Almeida-Santana and Moreno-Gil, 2017; Meleddu et al., 2015). In a vast and multidimensional subject like a tourism destination that involves many services such as hotel services, transportation, etc., finding out the proper attributes and factors influencing the tourist's loyalty gains importance (Tasci, 2017). In an early investigation of previous studies, among 17 proposed factors, just three showed significant relation to destination loyalty; safety, different cultural experience, convenient transportation. A blaze of studies have recognized satisfaction as the main factor contributing to tourist loyalty (Almeida-Santana and Moreno-Gil, 2018; Chi and Qu, 2008; Hultman et al., 2015; Rajesh, 2013; Ramseook-Munhurrun et al., 2015; Sun et al., 2013; Velázquez et al., 2011; Yoon and Uysal, 2005). In a study, Rajesh (2013) investigated the impact of tourist perceptions, the destination image and satisfaction on tourist loyalty, and proposed a model to explain the antecedents leading up to destination loyalty. In his model, the travel environment, natural attractions, historical and cultural attractions, accessibility, infrastructure, relaxation, price, and value were introduced as image attributes, and attractions, accessibility, lodging, dining, the environment, shopping, event, and activities as satisfaction attributes, following a research by Chi and Qu (2008). Also, the studies of Sun et al. (2013) and Ramseook-Munhurrun et al. (2015) suggest both a direct effect and an indirect effect of perceived value through the moderating role of satisfaction on destination loyalty. Service quality also has proven to promote word of mouth and cause repeat purchase (Cole and Illum, 2006; Velázquez et al., 2011). Hsu et al. (2009) in an attempt to introduce a framework to predict tourism loyalty using the BN, however, indicate three factors contributing to loyalty: Customer relationship management (CRM), web function and local characteristics. Other factors like novelty seeking, place attachment, information search and demographic characteristics (Almeida-Santana and Moreno-Gil, 2017; Mohamed and Shaker, 2017; Yuksel et al., 2010) also have been mentioned as factors affecting loyalty, but there were

VOL. $\mathbf{m}$ NO. $\mathbf{m} 2021 \mid$ JOURNAL OF TOURISM FUTURES $\mid$ PAGE 3 
lacks for an uncertainty analysis for evaluating the contribution of each factors to the loyalty and its effect on post-tourism behavior such as likelihood of travelers returnee.

\section{Bayesian network}

The BN is a graphical model for reasoning under uncertainty that uses causal relationships (represented by directed edges) among components of a system (represented by chance nodes). The BN estimates the joint probability distribution of a set of random variables based on the conditional independencies and the chain rule, as stated in Eq. (2). An extensive review of the BN and probabilistic knowledge elicitation including its applications in uncertainty modeling is provided by Barber (2012).

$$
P\left(X_{1}, X_{2}, \ldots, X_{n}\right)=\prod_{i=1}^{n} P\left(X_{i} \mid \operatorname{pa}\left(X_{i}\right)\right)
$$

where, $p a\left(X_{i}\right)$ is the parent set of variable $X_{i}$. As an example, the joint probability distribution of the random variables $X_{1}-X_{4}$ shown in Figure 1 is estimated by $P\left(X_{1}, X_{2}, X_{3}, X_{4}\right)=P\left(X_{1}\right) P\left(X_{2}\right) P\left(X_{3} \mid X_{1}, X_{2}\right) P\left(X_{4} \mid X_{3}, X_{2}\right)$

In case new information becomes available for one or more chance nodes, the $B N$ is able to update the joint probability based on the Bayes' theorem:

$$
P(X \mid E)=\frac{P(X, E)}{\sum_{X} P(X, E)}
$$

\section{Methodology: loyalty prediction tool}

In this part, a framework is presented based on which destination loyalty uncertainty can be assessed. To this end, a loyalty model based on the essential influence parameters which best describe destination loyalty attributes is introduced; then a questionnaire based on the proposed conceptual destination loyalty model and answered by experts for obtaining raw data to be fed into the constructed probability network using Bayesian approach is designed. Lastly, the developed loyalty model is set on the BN, and the obtained data from the questionnaire is fed to it to see how different factors have contributed to loyalty uncertainty and how loyalty may perform in the various given scenarios.

\section{Figure 1 A schematic representation for the BN based on uncertain factors and their} hypothetical casual relation

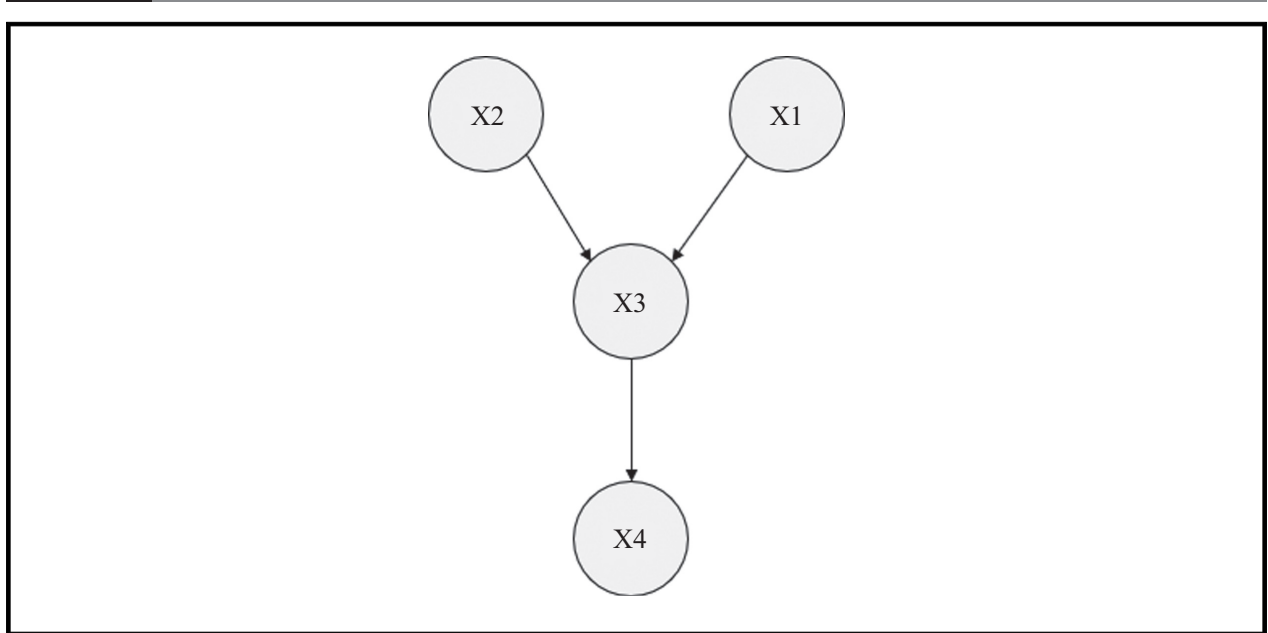

PAGE 4 |JOURNAL OF TOURISM FUTURES $\mid$ VOL. m. NO. 2021 
The developed BN has the capacity to evaluate the performance of loyalty in terms of identified influence factors and, in this respect, estimate the most optimum scenario of loyalty destination; thus, it can provide a great opportunity for DMOs and policy makers in the field of tourism to identify the most influential factors contributing to loyalty and plan to focus more on them.

\section{Qualitative loyalty model and survey analysis}

The loyalty model is introduced in a way to focus more on the destination attributes and components. In order to perceive the causal relation between influencing factors in the destination loyalty assessment, a qualitative framework is developed. According to research conducted by Rajesh (2013) and Chi and Qu (2008), a few image attributes and satisfaction attributes were highlighted. However, in this study the imperative factors are observed to form a systematic qualitative loyalty framework that enables integration of the model with the $\mathrm{BN}$ for loyalty prediction.

There should be prior knowledge for the BN to run. This prior knowledge is assigned to the independent variables - parent nodes - and, based on this prior knowledge and conditional tables within the BN, the estimation for dependent variables are conducted. In other words, the BN consists of children nodes and parent nodes. For the BN to compile, raw data of parent nodes should be provided and based on conditional relations between different nodes, the state of children nodes (second or third order factors) are estimated. Based on this fact, items of the questionnaire cover only the image factors (IFs) that are considered as parent nodes of the proposed BN. This means that the obtained data for IFs are sufficient for the BN to run. For the prior knowledge in the $\mathrm{BN}$, a questionnaire based on the image attributes connected with satisfaction attributes can be proposed to help generate logical statistical numbers that assist for the third part of the methodology - destination loyalty prediction. The desired questionnaire respondents will be asked to rank from scale 1 to 5 according to their agreement to the statements. The results will be further analyzed for implementation in Bayesian inference. An illustration of the loyalty model and the image parts responsible for constructing the questionnaire items is represented in Figure 2.

\section{Questionnaire design for image factors}

IFs have been considered parent nodes in the proposed BN and therefore needed to be fed by prior knowledge. In this study, the required data for IFs have been obtained through questionnaires that the field experts responded to. Experts who were asked to answer the questionnaire were among experienced tour guides and prolific academicians. These experts were chosen as they have a good knowledge of inbound tourists' attitudes traveling to Iran. The questionnaire items

Figure 2 Determining influencing factors and their causal relationship for elaborating loyalty of the destination city

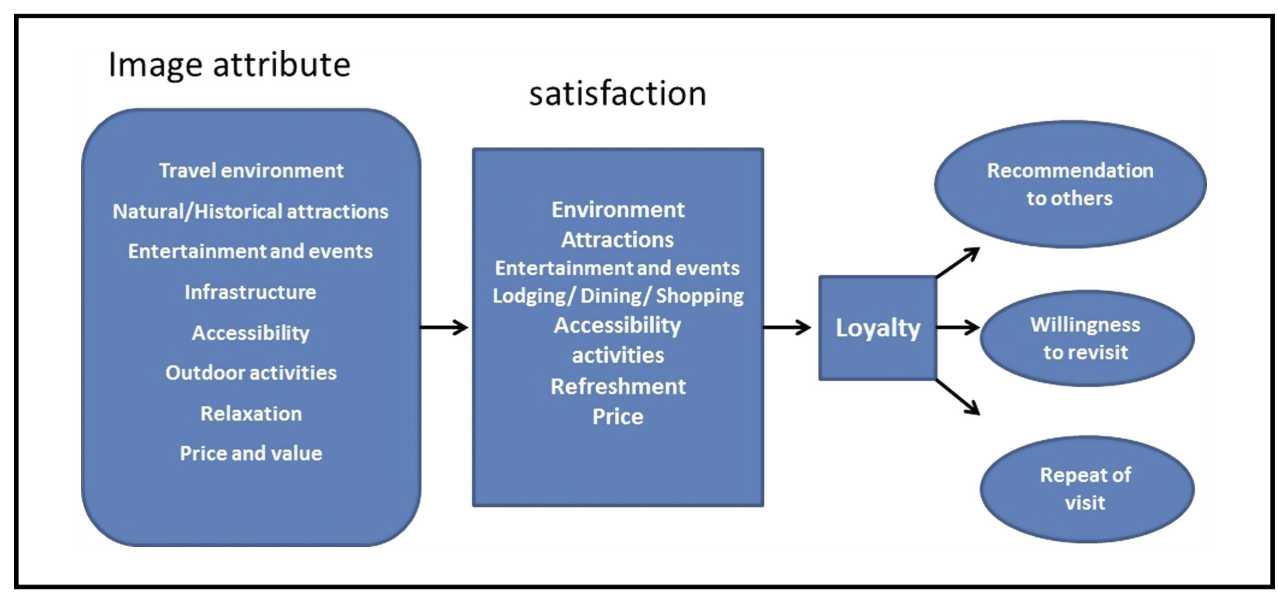

VOL. $\mathbf{m}$ NO. $\mathbf{m} 2021 \mid$ JOURNAL OF TOURISM FUTURES $\mid$ PAGE 5 
were adopted from Chi and Qu (2008) and Rajesh's (2013) studies. As illustrated in Figure 2, the travel environment, natural/historical attractions, entertainment and events, infrastructure, accessibility, outdoor activities, relaxation, price and value were the factors that have been addressed in the questionnaire. The items of the questionnaire related to each IF are illustrated in Figure 3.

In the next step, the constructed questionnaires are distributed to experts. These experts are asked to rank each item based on a five-point scale, indicating how much they agree to the statements: 1 being strongly disagree and 5 being strongly agree. As subjectivity and variability of expert judgment could influence the data obtained, Dempster-Shafer theory is implemented on the data to reduce the conflict of judgments. The basic probability assignment (BPA) for each individual IF is obtained from the expert judgment. As the IF is assigned to five different possibilities - strongly agree, agree, undecided, disagree and strongly disagree - the BPA is assigned by an expert for each of these states and expresses the degree of expert opinion. The BPA is represented by $m\left(p_{i}\right)$ and can be characterized by the following equation:

$$
m\left(p_{i}\right) \rightarrow[0,1] ; \quad m(\varphi)=0 ; \quad \sum_{p_{i} \subseteq p} m\left(p_{i}\right)=1
$$

The DST combination rule is then used to accumulate the different knowledge sources according to individual expert degrees of belief. If there are $n$ different knowledge sources that are to be combined, the orthogonal sum combination rule will be as shown in the following Eq. (4):

$$
m_{1-n}=m_{1} \oplus m_{2} \oplus \ldots \oplus m_{n}
$$

The DST combination rule by implementing a normalizing factor $(1-k)$ creates a consistency among the multiple knowledge sources and disregards all conflicting evidence through normalization. Considering all knowledge sources independent, the DST combination rule uses AND-type operators. For example, if $m_{1}\left(p_{a}\right)$ and $m_{2}\left(p_{b}\right)$ are two sets of evidence for the same event collected from two different sources; the DST combination rule uses the relation in Eq. (3) to combine the evidence:

$$
\left[m_{1} \oplus m_{2}\right]\left(p_{i}\right)\left\{\begin{array}{cc}
0 & \text { for } p_{i}=\varphi \\
\frac{\sum_{p_{a} \cap_{b}=p_{i}} m_{1}\left(p_{a}\right) m_{2}\left(p_{b}\right)}{1-k} & \text { for } p_{i} \neq \varphi
\end{array}\right.
$$

\section{Bayesian network framework}

In this part, a Bayesian framework based on the proposed qualitative loyalty is projected. The image attributes are considered prior information in the framework, as they directly affect the satisfaction attributes. Based on the expert judgment points derived from the designed questionnaire, a set of IFs identified as IF $=[A 1, B 1, C 1, D 1, E 1, F 1, G 1, H 1]$ has a potential contribution for variating the tourism satisfaction factors (SFs) according to the set of SF $=[A 2, B 2$, C2, D2, E2, F2, G2, H2] in a target destination (see Table 1). For this reason, there are conditional links from each array of IFs to all member of SFs in the network as depicted in Figure 4. Accordingly, the uncertainty of destination loyalty is modeled by the influence link derived from the set of SF members. Regarding the attributes of loyalty (Almeida-Santana and Moreno-Gil, 2017; Meleddu et al., 2015), three factors are considered in the network for the direct conditional influence of the destination loyalty; these factors represent the most important characteristics of loyalty to a destination and are estimated by three modes of returnee, intention and recommendation. The developed network will be able to analyze the behavior of destination loyalty and its antecedent factors. In one common analysis, the state of loyalty is improved to its optimum state, therefore estimating the most effective IFs of the considered destination and alleviating the associated uncertainty regarding IFs leading to destination loyalty. The description of the nodes in the developed BN is abbreviated according to Table 1.

PAGE 6 | JOURNAL OF TOURISM FUTURES $\mid$ VOL. $\mathbf{m}$ NO. $\mathbf{m} 2021$ 


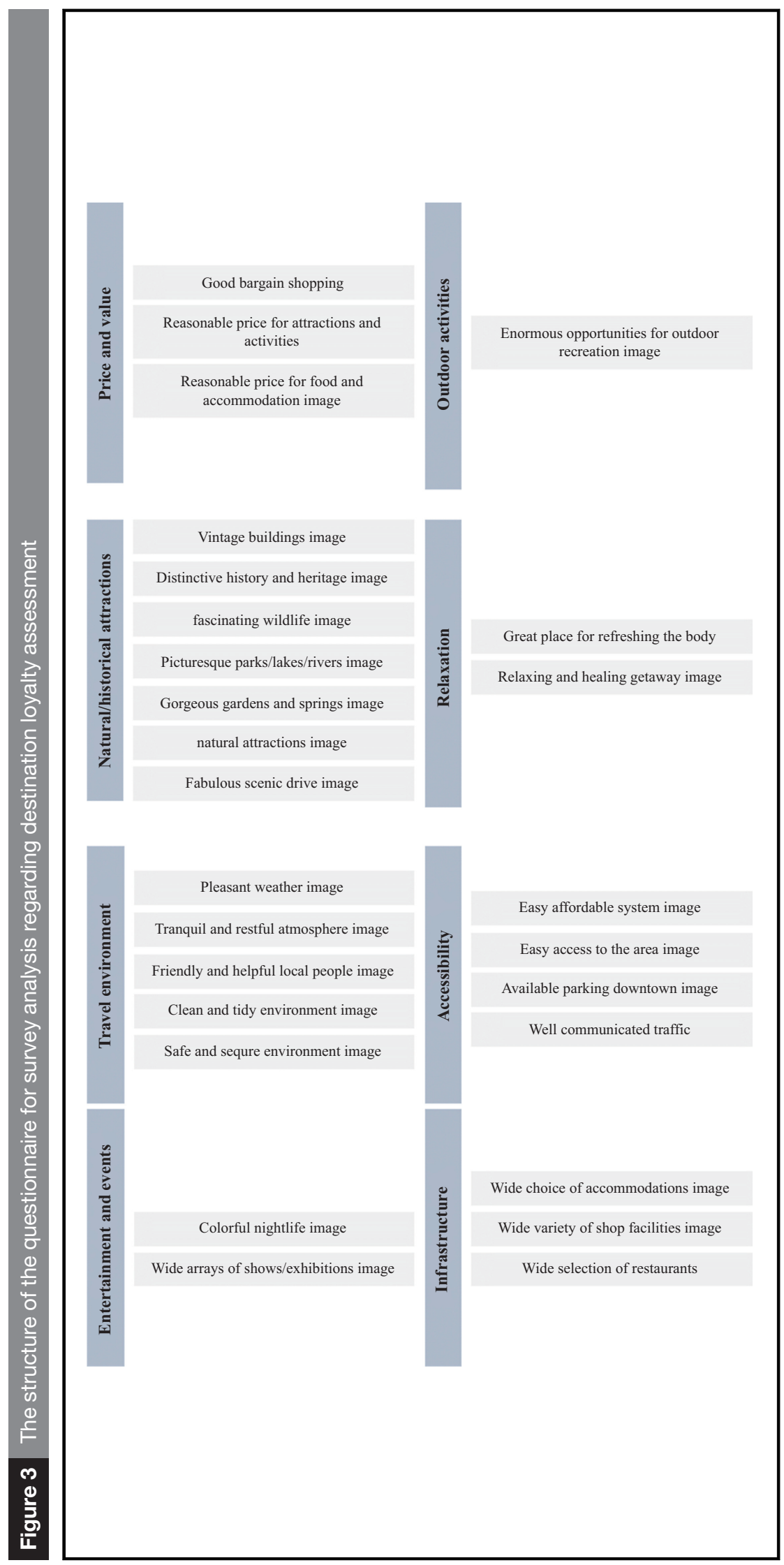

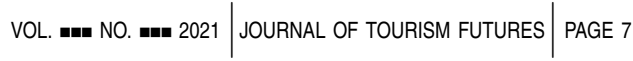


Table 1 The definition of the IF and SF sets that were considered in the developed network

Travel environment image

Natural/historical attractions image

Entertainment and events image

Infrastructure image

Accessibility image

Relaxation image

Outdoor activities image

Price and value image
A1

B1

C1

D1

E1

F1

G1

$\mathrm{H} 1$
Environment satisfaction

Attractions satisfaction

Activities and events satisfaction

Shopping/lodging/dining satisfaction

Accessibility satisfaction

Refreshment satisfaction

Activities satisfaction

Price satisfaction
A2

B2

$\mathrm{C} 2$

D2

E2

F2

G2 $\mathrm{H} 2$

\section{Figure 4 Developed BN for prediction loyalty of tourist destination respect to essential} influencing factors

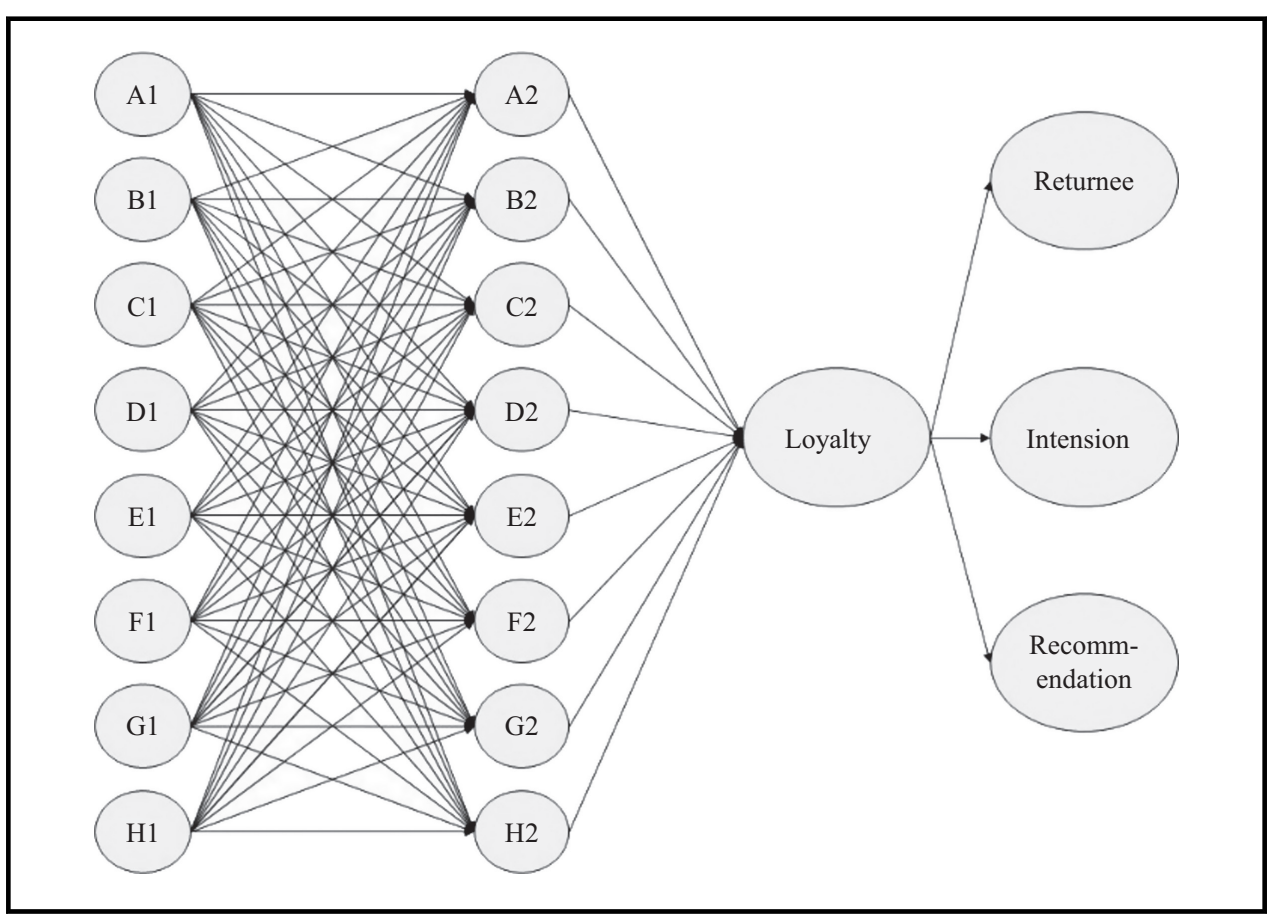

\section{Application of the framework: a case study}

To demonstrate the application of the methodology, a case study is adopted for loyalty prediction of tourists coming to Tehran. Tehran has high potential in attracting tourists, as it has untouched historical, cultural and natural attractions. However, there is still need to optimize the marketing and policy making approaches for this destination. To achieve this objective, the proposed framework is developed to help improve the condition of destination loyalty in Tehran. The remaining of this section will describe the loyalty behavior of Tehran as a newly noticed destination regarding the associated uncertainty factors.

The primary data for the BN were obtained through the process described in the questionnaire design section. In the questionnaire for each item related to IFs, five options from strongly agree to strongly disagree, and weighted from 1 to 5 exist. According to the weights given by experts to each item of the questionnaire and normalization of data based on Dempster-Shafer theory, the results were, then, further described in percentage and summarized in Table 2. In the questionnaire the travel environment image is assessed using five items, natural/historical attractions image using seven items, entertainment and event image using two items, infrastructure image using three items, accessibility image with four items, relaxation image with two items, outdoor activities image 
Table 2 Contribution of the responders to the IFs according to the questioner items

$\begin{array}{llr}\text { Travel environment 65.6\% } & \text { Safe and secure environment image } & 46 \% \\ & \text { Clean and tidy environment image } & 52 \% \\ & \text { Friendly and helpful local people image } & 95 \% \\ & \text { Tranquil and restful atmosphere image } & 60 \% \\ & \text { Pleasant weather image } & 75 \% \\ \text { Natural/historical attractions } & \text { Fabulous scenic drive image } & 90 \% \\ 81.5 \% & \text { Breathtaking scenery and natural attractions image } & 90 \% \\ & \text { Gorgeous historical gardens image } & 85 \% \\ & \text { Picturesque parks/lakes/rivers image } & 80 \% \\ & \text { Unspoiled wilderness and fascinating wildlife image } & 70 \% \\ & \text { Distinctive history and heritage image } & 90 \% \\ \text { Entertainment and events 35\% } & \text { Vintage buildings and sites image } & 94 \% \\ & \text { Wide arrays of shows/exhibitions image } & 45 \% \\ \text { Infrastructure 56\% } & \text { Colorful nightlife image } & 25 \% \\ & \text { Wide selection of restaurants/cuisine image } & 62 \% \\ \text { Accessibility 34.5\% } & \text { Wide variety of shop facilities image } & 50 \% \\ & \text { Wide choice of accommodations image } & 56 \% \\ & \text { Well communicated traffic flow and parking information image } & 30 \% \\ & \text { Available parking downtown image } & 30 \% \\ \text { Relaxation 51\% } & \text { Easy access to the area image } & 46 \% \\ & \text { Easy-to-use and affordable trolley system image } & 32 \% \\ \text { Outdoor activities } 60 \% & \text { Relaxing day spa and healing getaway image } & 46 \% \\ \text { Price and value 60.6\% } & \text { Great place for soothing the mind and refreshing the body } & 56 \% \\ & \text { image } & \\ & \text { Enormous opportunities for outdoor recreation image } & 60 \% \\ & \text { Reasonable price for food and accommodation image } & 60 \% \\ & \text { Reasonable price for attractions and activities } & 70 \% \\ & \text { Good bargain shopping } & 52 \%\end{array}$

with one item, and price and value image with three items. The number of items for each contribution was defined based on the expert opinions and their concern for the image contributions to loyalty perception. These judgments were made based on the compatibility of the items with Tehran as a destination.

In order to perform loyalty estimation with the developed BN, the root nodes of the network for IFs are fed by prior knowledge obtained from experts. Then, to consider the conditional dependency of the satisfaction factors with the images, the logic value of zeros (not satisfied) and ones (satisfied) are considered according to the expert judgment perception on the contribution of satisfaction on the loyalty of the destinations. This concept was previously suggested by Friis-Hansen (2000) to fill up the conditional probability tables (CPTs) and to start the Bayesian inference. This will cause the first compile of the network to find the joint probability of satisfaction nodes as perceived by expert judgments. Finally, the CPT of the loyalty node and consequences nodes of loyalty attributes are filled by the "And-gate" concept (Khakzad et al., 2011) to find the most critical scenario that helps estimate better tourist loyalty observance. Given the information fed into the BN, Tehran's anticipated loyalty as a destination is $41 \%$ based on the prior knowledge collected from survey observations. The loyalty attributes percentage of contribution are all calculated through the network. The returnee repeat visit stands as $67 \%$ encouraged, the intention to revisit stands as $76 \%$, and recommendation to others as $92 \%$, being the most influential attribute of Tehran destination loyalty. The results are shown in Figure 5.

In a back-propagation analysis, given that it is aimed to reach a hundred percent loyal travelers, the most important and influential IFs that contribute to a hundred percent loyalty, are recognized. As illustrated in Figure 6, which shows the back-propagated Tehran loyalty BN, A1 (travel environment) and B1 (natural/historical attractions) are considered as the most prominent factors leading to high percentage of loyalty to Tehran as a tourist destination. C1, D1, E1 and F1 contribute to loyalty optimization much less, and $\mathrm{G} 1$ and $\mathrm{H} 1$ have no contribution at all. To analyze 


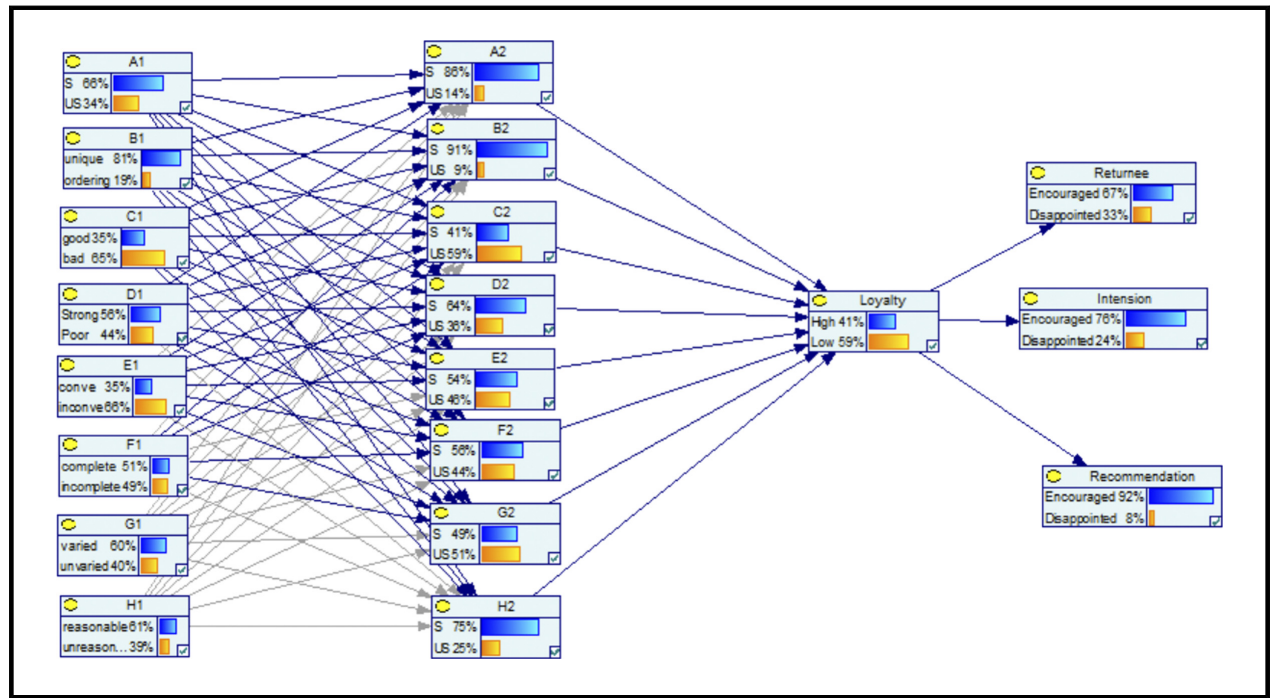

Figure 6 The back-propagation analysis for estimating optimized improvement of tourism loyalty

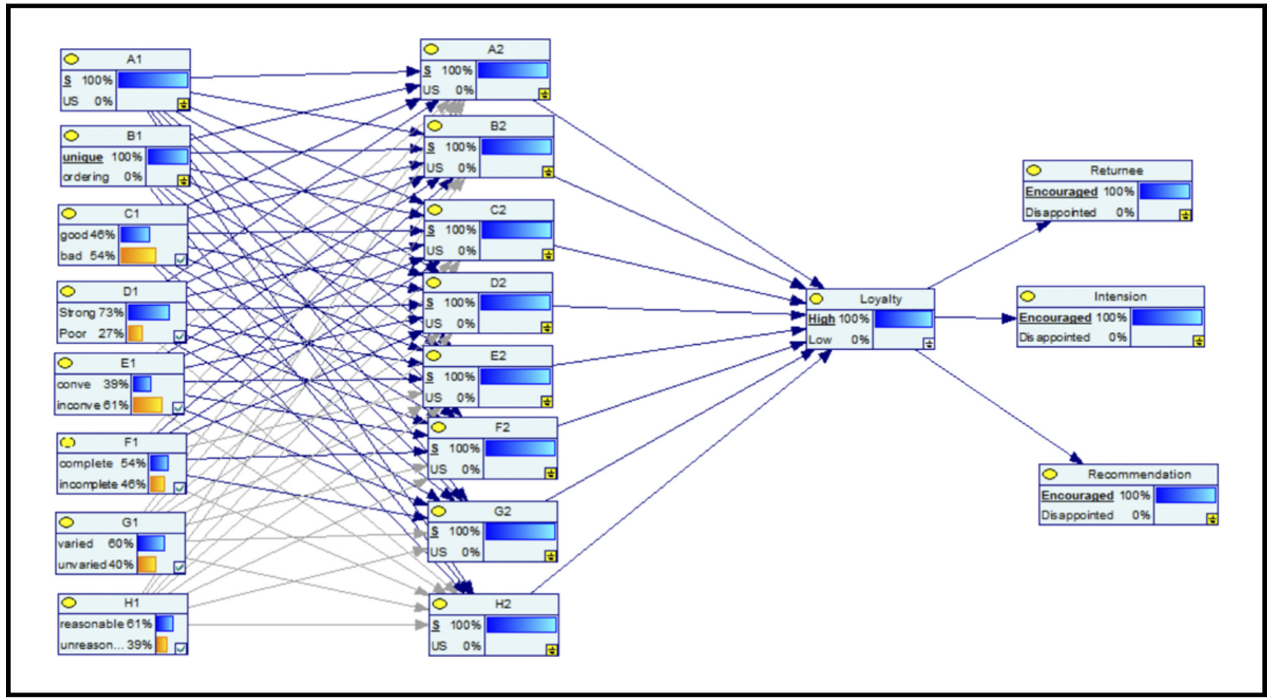

the results better and to give a clearer representation of the back-propagated BN result, the states of IFs in the back-propagated BN are mapped out on a line graph, represented in Figure 7. As represented in this line graph, A1(travel environment), B1(natural/historical attractions) and D1 (infrastructure) contribute the most in raising the state of loyalty to its optimum level. This graph also informs that for optimization of the loyalty, it is not necessary to consider every IF influential, and there is no need for every IF to be in its most optimized state. In other words, it is possible to define a scenario for IFs' behaviors when the optimum state of destination loyalty is given as new evidence in the BN. As a result of this analysis, the IFs that have the most contribution to improvement of Tehran destination loyalty will stand out. 


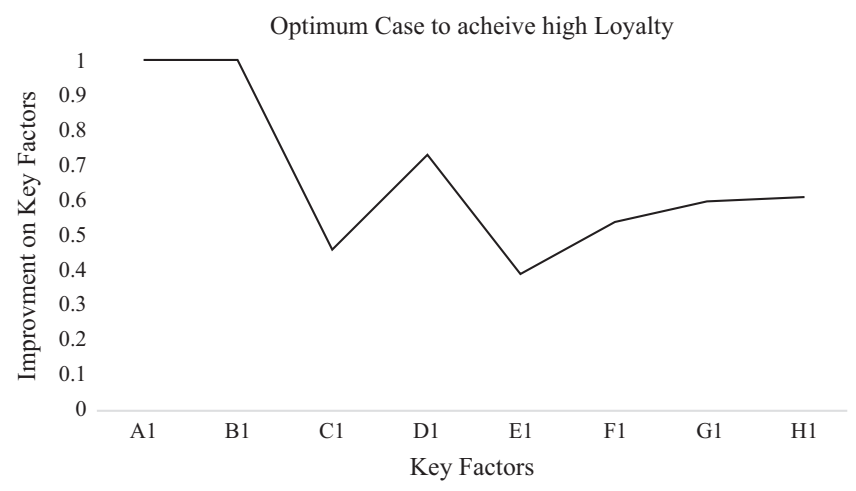

To compare this optimized state of IFs with experts' judgments and also to point out the critical limit of these factors, another graph is rendered in Figure 8. In this plot, the improved IFs contributing to improved loyalty, deducted from back-propagation analysis, are shown with black dots; also, experts' judgments speculations before improvement are depicted with small triangles and the worst-case scenario of the loyalty status, drawn from another back-propagation analysis of the BN where destination loyalty is considered to be zero percent for the selected destination city, is shown with a straight line. The worst-case scenario of Tehran destination loyalty is, in fact, an illustration of the critical condition that would result in no satisfaction for travelers.

Figure 9 represents a line graph showing results inferred from forward propagation analysis of the $\mathrm{BN}$. On the $Y$ axis the state of loyalty is shown according to the $X$ axis for two different conditions (1) the contribution of each IF in its best improved condition and (2) the influence of cumulative evidence on progressive improvement of series of image parameters for the destination loyalty. The unbroken line shows the growth of loyalty when only each factor separately is taken into consideration as it is the best condition in the $\mathrm{BN}$, each being individually one hundred percent effective on satisfaction and in return on loyalty. These key factors' influences are shown by $\mathrm{H} 1$ to A1 on the graph. The broken line from e1 to e8 show the influence of factors cumulatively, which means $\mathrm{e} 8$ is the successive addition of $\mathrm{H} 1$ to $\mathrm{A} 1$. This graph shows how important the evidence $\mathrm{e} 6$ to e8 are for optimization of Tehran's destination loyalty.

Finally, to demonstrate the most influential factors on loyalty attributes - recommendation, intention to revisit, repeat of visit - each factor is optimized to a $100 \%$ state in order to check the changes happening to these attributes. The results were further represented in a line graph (Figure 10). As it

Figure 8 Comparison study for evaluation of possible scenarios for improving loyalty of Tehran as a destination of tourism

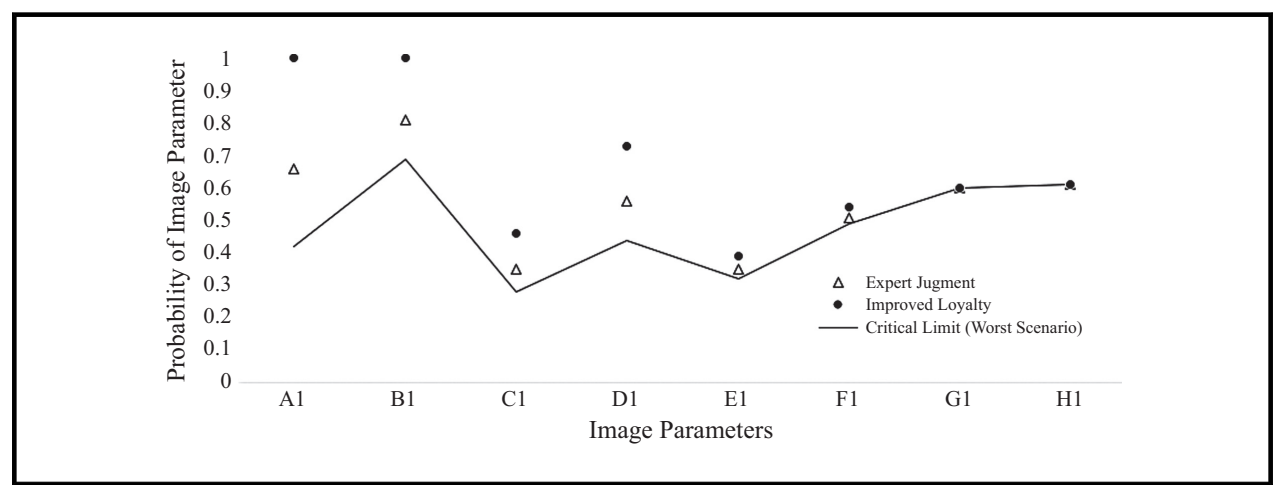

VOL. mo. 2021 NOURNAL OF TOURISM FUTURES| PAGE 11 
Figure 9 Effect of individual key factors and cumulative evidence on destination loyalty growth

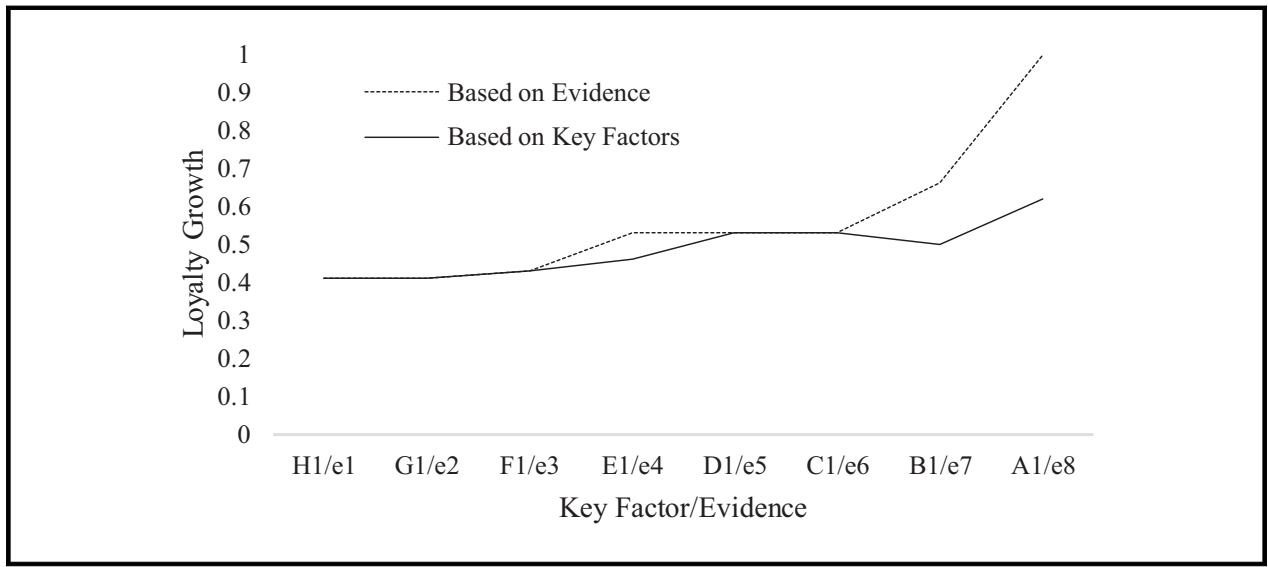

\section{Figure 10 Effective analysis of royalty attributes improvement}

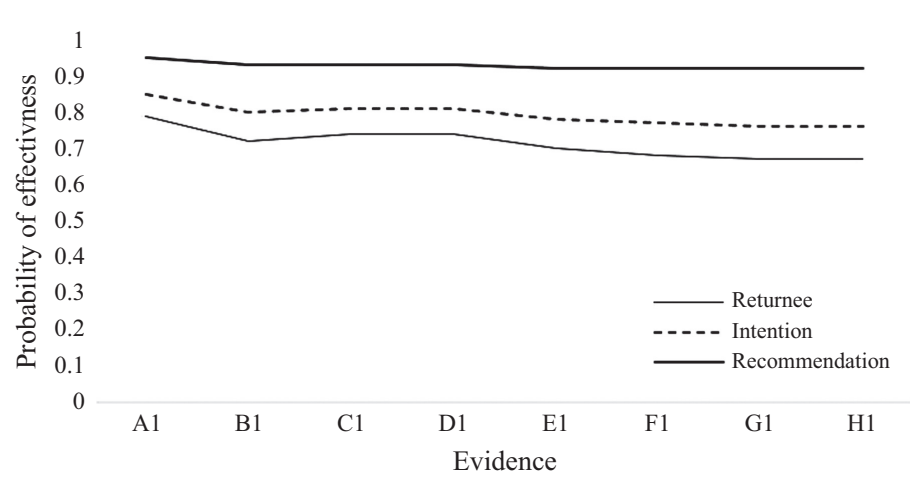

is shown in the graph, the travel environment image proved to be the most influential factor. In its optimized state, it makes the probability of repeat of visit stand at $79 \%$, intention to revisit at $85 \%$ and recommendation to others at $95 \%$. The entertainment/event image along with the infrastructure image also showed high influence on loyalty attributes. In a 100\% optimized state of the entertainment/event image, the probability of repeat of visit stands at $74 \%$, intention to revisit at $81 \%$ and recommendation to others at $93 \%$. For the $100 \%$ optimized infrastructure image, the result is the same as that of the entertainment/event image. This result is very important for decision makers in the field of tourism showing them where to focus when they want to increase the rate of destination loyalty.

\section{Conclusion}

An important part in tourism marketing is destination marketing. Destination marketing has proved to be complicated due to the fact that many tourist stakeholders are entangled in it, some of which may even have conflicting interest. As a result, the role of destination policy makers to introduce a comprehensive plan considering all destination stakeholders becomes more prominent. In this regard, destination loyalty as an important marketing tool and a competitive advantage for destinations comes into attention. 
High destination loyalty is considered a strong competitive advantage tool for organizations, companies and destinations; so recognizing the most influential factors in shaping high loyalty and predicting its behavior play an important role in tourism marketing. This paper attempts to provide a framework through which explaining the behavior of a destination loyalty and its antecedents would be possible.

Although many articles have tried to find out a model describing factors contributing to loyalty, very few have tried to analyze its behavior given probabilistic conditions.

This paper first introduces a loyalty model in which the destination image and traveler satisfaction are involved in shaping loyalty. After that, this loyalty model is mapped out on a probabilistic tool, namely the BN. The image attributes in the network are considered the prior knowledge in the network and are fed with the data obtained from the questionnaire survey. Tehran also has been selected as a case study destination. The results pertaining to Tehran's destination loyalty obtained from the BN show that Tehran's destination loyalty stands as $41 \%$. In a backward analysis approach, to predict the behavior of its antecedents' factors, destination loyalty was set to the $100 \%$ state. In this analysis, the most influential factors were recognized as the travel environment image, natural/historical attractions image and, to a lower extent, the infrastructure image.

\section{Managerial implications}

This study, besides providing academic contributions, has insightful implications for practitioners in the tourism sector. Given the low state of tourist destination loyalty toward Tehran, the most influential factors to improve this loyalty were estimated. In the backward analysis of the constructed BN, the results showed that in the scenario of a hundred percent destination loyalty of Tehran, two IFs of the travel environment image and natural/historical attractions image were the most contributing and influential factors for improving loyalty state to its optimum level. Also the critical limits of IFs were estimated seeing another scenario in the BN where the state of loyalty was put at its lowest level which is zero. This finding can, alongside the previous finding, help different tourism stakeholders and policy makers in Tehran to find a balanced plan to focus more on most influential IFs to improve these factors and also work on other IFs to the extent needed for an optimum destination loyalty level.

\section{References}

Abaei, M.M., Arzaghi, E., Abbassi, R., Garaniya, V., Javanmardi, M. and Chai, S. (2018), "Dynamic reliability assessment of ship grounding using Bayesian inference", Ocean Engineering, Vol. 159, pp. 47-55.

Almeida-Santana, A. and Moreno-Gil, S. (2017), "New trends in information search and their influence on destination loyalty: digital destinations and relationship marketing", Journal of Destination Marketing and Management, Vol. 6 No. 2, pp. 150-161.

Almeida-Santana, A. and Moreno-Gil, S. (2018), "Understanding tourism loyalty: horizontal vs. destination loyalty", Tourism Management, Vol. 65, pp. 245-255.

Arzaghi, E., Abaei, M.M., Abbassi, R., Garaniya, V., Binns, J., Chin, C. and Khan, F. (2018), "A hierarchical Bayesian approach to modelling fate and transport of oil released from subsea pipelines", Process Safety and Environmental Protection, Vol. 118, pp. 307-315.

Assaf, A.G. and Tsionas, E.G. (2015), "Incorporating destination quality into the measurement of tourism performance: a Bayesian approach", Tourism Management, Vol. 49, pp. 58-71.

BahooToroody, A., Abaei, M.M., Arzaghi, E., BahooToroody, F., De Carlo, F. and Abbassi, R. (2019), "Multilevel optimization of maintenance plan for natural gas system exposed to deterioration process", Journal of Hazardous Materials, Vol. 362, pp. 412-423.

Baggio, R., Scott, N. and Cooper, C. (2010), "Improving tourism destination governance: a complexity science approach", Tourism Review, Vol. 65 No. 4, pp. 51-60.

Baloglu, S. (2002), "Dimensions of customer loyalty: separating friends from well wishers", Cornell Hotel and Restaurant Administration Quarterly, Vol. 43 No. 1, pp. 47-59. 
Barber, D. (2012), Bayesian Reasoning and Machine Learning, Cambridge University Press, February 2.

Bidhendi, R.S., Farahani, F.A., Talebian, M.H., Ghalibaf, M.B. and Amiri, S.R.S. (2021), Strategic Tourism Management of Tehran; Challenges and Opportunities.

Brida, J.G., Pulina, M., Riãno, E. and Zapata-Aguirre, S. (2012), "Cruise visitors' intention to return as land tourists and to recommend a visited destination", Anatolia e An International Journal of Tourism and Hospitality Research, Vol. 23 No. 3, p. 395e412.

Chanpariyavatevong, K., Wipulanusat, W., Champahom, T., Jomnonkwao, S., Chonsalasin, D. and Ratanavaraha, V. (2021), "Predicting airline customer loyalty by integrating structural equation modeling and Bayesian networks", Sustainability, Vol. 13 No. 13, p. 7046.

CHHTOI (2018), "Cultural heritage, Handicrafts and tourism organization of Iran", available at: http://www. ichto.ir/.

Chi, C.G.Q. and Qu, H. (2008), "Examining the structural relationships of destination image, tourist satisfaction and destination loyalty: an integrated approach", Tourism Management, Vol. 29 No. 4, pp. 624-636.

Cole, S.T. and Illum, S.F. (2006), "Examining the mediating role of festival visitors' satisfaction in the relationship between service quality and behavioral intentions", Journal of Vacation Marketing, Vol. 12 No. 2 , pp. 160-173.

Eusebio, C. and Vieira, A.L. (2013), "Destination attributes' evaluation, satisfaction and behavioural intentions: a structural modelling approach", International Journal of Tourism Research, Vol. 15, p. 66e80.

Friis-Hansen, A. (2000), "Bayesian networks as a decision tool in Marine applications", Ph. D. thesis, DTU, Denmark.

Gursoy, D., Chen, S.J. and Chi, G.C. (2014), "Theoretical examination of destination loyalty formation", International Journal of Contemporary Hospitality Management, Vol. 26 No. 5, pp. 809-827.

Hsu, F.M., Lin, Y.T. and Ho, T.K. (2012), "Design and implementation of an intelligent recommendation system for tourist attractions: the integration of EBM model, Bayesian network and Google Maps", Expert Systems with Applications, Vol. 39 No. 3, pp. 3257-3264.

Hsu, C.I., Shih, M.L., Huang, B.W., Lin, B.Y. and Lin, C.N. (2009), "Predicting tourism loyalty using an integrated Bayesian network mechanism", Expert Systems with Applications, Vol. 36 No. 9, pp. 11760-11763.

Hultman, M., Skarmeas, D., Oghazi, P. and Beheshti, H.M. (2015), "Achieving tourist loyalty through destination personality, satisfaction, and identification", Journal of Business Research, Vol. 68 No. 11, pp. 2227-2231.

Khakzad, N., Khan, F. and Amyotte, P. (2011), "Safety analysis in process facilities: comparison of fault tree and Bayesian network approaches”, Reliability Engineering and System Safety, Vol. 96 No. 8, pp. 925-932.

Kumar, V., Shah, D. and Venkatesan, R. (2006), "Managing retailer profitability-one customer at a time!", Journal of Retailing, Vol. 82 No. 4, pp. 277-294.

Leoni, L., BahooToroody, A., De Carlo, F. and Paltrinieri, N. (2019), "Developing a risk-based maintenance model for a natural gas regulating and metering station using Bayesian network", Journal of Loss Prevention in the Process Industries, Vol. 57, pp. 17-24.

Line, N.D. and Wang, Y. (2017), "A multi-stakeholder market oriented approach to destination marketing", Journal of Destination Marketing and Management, Vol. 6 No. 1, pp. 84-93.

Meleddu, M., Paci, R. and Pulina, M. (2015), "Repeated behaviour and destination loyalty", Tourism Management, Vol. 50, pp. 159-171.

Mohamed, A. and Shaker, B.M. (2017), "Novelty seeking, image and loyalty-The mediating role of satisfaction and moderating role of length of stay: international tourists' perspective", Tourism Management Perspectives, Vol. 23, p. 8.

Nielsen, J.J. and Sørensen, J.D. (2010), "Bayesian networks as a decision tool for O\&M of offshore wind turbines", Proceedings of the 5th International ASRANet Conference.

Popovic, O.B., Nikic, V., Bulatovic, I. and Delibasic, M. (2018), "Modeling perceived quality, customer satisfaction and probability of guest returning to the destination", Montenegrin Journal of Economics, Vol. 14 No. 1 , pp. 69-78. 
Prayag, G. and Ryan, C. (2012), "Antecedents of tourists' loyalty to Mauritius. The role and influence of destination image, place attachment, personal involvement, and satisfaction", Journal of Travel Research, Vol. 51 No. 3, p. 342e356.

Rajesh, R. (2013), "Impact of tourist perceptions, destination image and tourist satisfaction on destination loyalty: a conceptual model", PASOS. Revista de Turismo y Patrimonio Cultural, Vol. 11 No. 3, pp. 67-78.

Ramseook-Munhurrun, P., Seebaluck, V.N. and Naidoo, P. (2015), "Examining the structural relationships of destination image, perceived value, tourist satisfaction and loyalty: case of Mauritius", Procedia-Social and Behavioral Sciences, Vol. 175, pp. 252-259.

Shafia, S. and Seyyed Naghavi, M. (2019), "Intra-organizational branding model in Tehran's services and tourism sector”, Tourism Management Studies, Vol. 14 No. 46, pp. 79-109.

Smeral, E. (1988), "Tourism demand, economic theory and econometrics: an integrated approach", Journal of Travel Research, Vol. 26 No. 4, pp. 38-43.

Straub, D. (2005), "Natural hazards risk assessment using Bayesian networks", 9th International Conference on Structural Safety and Reliability (ICOSSAR 05).

Stylidis, D., Woosnam, K.M., Ivkov, M. and Kim, S.S. (2020), "Destination loyalty explained through place attachment, destination familiarity and destination image", International Journal of Tourism Research, Vol. 22 No. 5, pp. 604-616.

Sun, X., Chi, C.G.Q. and Xu, H. (2013), "Developing destination loyalty: the case of Hainan Island", Annals of Tourism Research, Vol. 43, pp. 547-577.

Tasci, A.D.A. (2017), "A quest for destination loyalty by profiling loyal travelers", Journal of Destination Marketing and Management, Vol. 6 No. 3, pp. 207-220.

Tyrrell, T.J. and Johnston, R.J. (2008), "Tourism sustainability, resiliency and dynamics: towards a more comprehensive perspective", Tourism and Hospitality Research, Vol. 8 No. 1, pp. 14-24.

Velázquez, B.M., Saura, I.G. and Molina, M.E.R. (2011), "Conceptualizing and measuring loyalty: towards a conceptual model of tourist loyalty antecedents", Journal of Vacation Marketing, Vol. 17 No. 1, pp. 65-81.

Weaver, D.B. and Lawton, L.J. (2011), "Visitor loyalty at a private South Carolina protected area", Journal of Travel Research, Vol. 50 No. 3, pp. 335-346.

Yoon, Y. and Uysal, M. (2005), "An examination of the effects of motivation and satisfaction on destination loyalty: a structural model”, Tourism Management, Vol. 26 No. 1, pp. 45-56.

Yuksel, A., Yuksel, F. and Bilim, Y. (2010), "Destination attachment: effects on customer satisfaction and cognitive, affective and conative loyalty”, Tourism Management, Vol. 31 No. 2, pp. 274-284.

Zwirglmaier, K., Straub, D. and Groth, K.M. (2015), "Framework for a Bayesian network version of IDHEAS", in Proceeding ESREL, No. 15.

\section{Further reading}

Akama, J.S. (1996), "Western environmental values and nature-based tourism in Kenya", Tourism Management, Vol. 17 No. 8, pp. 567-574.

\section{Corresponding author}

Mohammad Mahdi Abaei can be contacted at: mahdy.abaiee@gmail.com

For instructions on how to order reprints of this article, please visit our website: www.emeraldgrouppublishing.com/licensing/reprints.htm Or contact us for further details: permissions@emeraldinsight.com 